\title{
Erosion processes in black marl soils at the millimetre scale: preliminary insights from an analogous model
}

\author{
J. Bechet ${ }^{1, \dagger}$, J. Duc ${ }^{1}$, M. Jaboyedoff ${ }^{1}$, A. Loye ${ }^{1}$, and N. Mathys ${ }^{2}$ \\ ${ }^{1}$ University of Lausanne, Risk-group - ISTE - Institute of Earth Sciences, Lausanne, Switzerland \\ ${ }^{2}$ IRSTEA Grenoble, Unité de recherche Erosion Torrentielle, Neige et Avalanches, BP 76, \\ 38402 Saint Martin d'Hères, France \\ ${ }^{\dagger}$ Deceased on 28 March 2015 \\ Correspondence to: M. Jaboyedoff (michel.jaboyedoff@unil.ch)
}

Received: 22 January 2014 - Published in Hydrol. Earth Syst. Sci. Discuss.: 21 February 2014 Revised: 11 February 2015 - Accepted: 25 March 2015 - Published: 20 April 2015

\begin{abstract}
To investigate the millimetre-scale surface processes caused by natural rainfall, an undisturbed sample of badlands soil ( $1 \mathrm{~m}$ long, $0.5 \mathrm{~m}$ wide and $0.15 \mathrm{~m}$ thick) was carefully extracted. The sample is composed of black marl soil from a badlands area of the Draix Observatory (SE France). After extraction, the undisturbed sample was placed at the same slope angle $\left(45^{\circ}\right)$ as its original orientation and was then monitored for several processes via a terrestrial laser scanner (TLS) with millimetre-scale accuracy and resolution. This experiment identified several surface processes interpreted as micro-landslides, swelling of the black marl material and lateral expansion that closed desiccation cracks. These micro-processes illustrate the complexity of the surface micro-topography changes that control erosion and infiltration rates over time.
\end{abstract}

\section{Introduction}

Small black marl watersheds have strong responses to climate forcing (Malet et al., 2007). This study aims to better understand the erosional behaviour and the micromorphological evolution of these materials caused by microscale mass movements in response to precipitation. The goal of this experiment was to extract an undisturbed sample of black marl and expose this material to a natural rainfall event in order to monitor the sample's surface evolution using a 3-D laser scanner. This monitoring has permitted us to study the micro-topographic surface deformation and erosion processes that may have an impact on infiltration rates during rainfall events (Mitchell and van Genuchten, 1993; Römkens and Prasad, 2006). In addition, these surface changes may also play a role in the triggering of landslides (Galeandro et al., 2014). Contrary to the original intention, the duration of the experiment and the rainfall intensity did not permit investigation of splash erosion, which can be important when rainfall is intense (Selby, 1993), because its effect was below the resolution of our acquisition and because the intensity of the rainfall was rather low.

In the past, several studies of artificial rain simulations have been performed at the Draix Observatory (ORE Draix), which is dedicated to the research of mountain hydrology and erosional processes. Previous studies focused on the measurement of sediment transport (Oostwoud Wijdenes and Ergenzinger, 1998) and runoff as a function of precipitation (Mathys et al., 2005). The badlands ground surface evolution has already been monitored during rainfall simulations by using a pin-type micro-relief meter and photography (Torri et al., 1999; Mathys et al., 2005), but these tools were not able to reach the same precision as a laser scanner. Recent studies have shown the potential for observing and characterising erosional processes at the level of micro-topography using a laser scanner (Schmid et al., 2004; Barneveld et al., 2013).

The soil sample was extracted from the Draix experimental site (ORE Draix, IRSTEA), a badlands area near the city of Digne-les-Bains in the southern French Alps. The experiment was performed in Lausanne (Switzerland), where the precipitation is similar to the Alpine region. For the monitoring of the sample surface, a terrestrial laser scanner (TLS) was used to (1) identify the millimetre-scale processes 



Figure 1. (a) View of the sample collection process, the metal case $(1 \mathrm{~m} \times 0.5 \mathrm{~m} \times 0.20 \mathrm{~m})$, and the approximate orientation of the bedding. The bottom plate is partially inserted. (b) View of the soil sample with an inclination of $45^{\circ}$ during the rainfall event. (c) Position of the TLS, which is protected from rainfall by a tent, relative to the metal case.

that control erosion and infiltration by (2) quantifying the swelling of the material in the marls during rainfall events and (3) mapping all possible modifications of the terrain surface.

\section{Geological setting}

The badlands near the village of Draix are composed of weathered black marls of Middle Jurassic age (CallovianOxfordian). The black marl formation is more than $2000 \mathrm{~m}$ thick in certain places (Antoine et al., 1995). The study site has no vegetal cover, and the regolith is usually approximately $40 \mathrm{~cm}$ to $1 \mathrm{~m}$ thick (Maquaire et al., 2002; Antoine et al., 1995). The upper approximately $10 \mathrm{~cm}$ of the regolith is loose detrital material composed of local clasts and platelets (Maquaire et al., 2002). This regolith corresponds to a sandy loam when it has been exposed for long enough to be disaggregated by weathering (Antoine et al., 1995). When the upper regolith layer is fresh, it can be considered loamy sand or sand. Below the regolith is a layer of plate-like unstructured rock. Finally, compacted regolith $10-20 \mathrm{~cm}$ thick lies in contact with the bedrock (Maquaire et al., 2002). The clay size fraction of the black marls located in this region has been found to be $35 \pm 5 \%$ (Caris and Van Asch, 1991), but the clay mineral content is approximately $10 \%$ and is primarily illite with traces of smectite and interstratified clay minerals (Antoine et al., 1995). During rainfall events, water infiltrates the ground and the material swells because of the behaviour of the fine-grained material and chemical reactions (Antoine et al., 1995). The loose upper-layer detrital material is very sensitive to erosion and is a good candidate for experiments involving surface processes imaging.

\section{Methods}

\subsection{Samples}

The sample of soil used for this experiment was extracted from a marl outcrop with a $45^{\circ}$ slope. The bedding is nearly normal to the face of the outcrop (Fig. 1a). Nevertheless, the loose detrital material at the surface does not display any identifiable bedding structure. The sample is $1 \mathrm{~m}$ long, $0.5 \mathrm{~m}$ wide and $0.15 \mathrm{~m}$ thick. To extract this sample of soil, a metal case was designed to keep the soil structure undisturbed (Fig. 1). The extraction was performed by pressing the bottomless box into the ground and inserting the bottom plate via tapping with a hammer to isolate a sample of the upper part of the regolith. This sample was stored in the laboratory in dry conditions, which were similar to natural conditions, for 3 months before the experiment started.

\subsection{Experiment design}

On 31 May 2011, the soil sample was exposed to natural rainfall from 11:01 to 17:47 LT (local time used throughout the text). During the experiment, the soil sample was kept in its metal extraction casing and was tilted at $45^{\circ}$ in order to obtain the same inclination as its in situ conditions.

The soil sample was scanned every $30 \mathrm{~min}$ using a groundbased TLS Leica ScanStation II, which produces point clouds $(x, y$, and $z$ data) in a three-dimensional space (Fig. 1c). The direction of the laser pulses' line of sight and the recorded time of flight determine the position of the measured points. The rainfall was measured by the weather station at the University of Lausanne (PluvioMADD2 from MADD Technology Sàrl, Yverdon-les-Bains, Switzerland), located $500 \mathrm{~m}$ from the experiment location.

The sample was dry at the beginning of the experiment. The total precipitation during the experiment was $5.5 \mathrm{~mm}$, which corresponds to approximately $1.3 \mathrm{~L}$ entering the metal 
Table 1. Summary of the TLS scans in the TLS campaign experiment on 31 June 2010. This table compiles the information concerning the scan time, the number of points before and after cleaning, the mean spacing between the points and the density of points.

\begin{tabular}{|c|c|c|c|c|c|}
\hline $\begin{array}{l}\text { Start of } \\
\text { acquisition } \\
\text { (duration } \\
\text { min) }\end{array}$ & $\begin{array}{r}\text { Number of } \\
\text { points } \\
\text { before } \\
\text { cleaning }\end{array}$ & $\begin{array}{c}\text { Mean } \\
\text { spacing } \\
(\mathrm{mm})\end{array}$ & $\begin{array}{l}\text { Distance } \\
\text { from TLS } \\
\quad(\mathrm{m})\end{array}$ & $\begin{array}{l}\text { Number of } \\
\text { points } \\
\text { after } \\
\text { cleaning }\end{array}$ & $\begin{array}{c}\text { Density } \\
\left(\text { pts cm }^{-2}\right)\end{array}$ \\
\hline 11:01 (8) & 601349 & 1 & 2 & 496391 & 84.84 \\
\hline $12: 00(2)$ & 149951 & 2 & 2 & 123233 & 21.06 \\
\hline $14: 00(2)$ & 149951 & 2 & 2 & 123477 & 21.10 \\
\hline $14: 30(2)$ & 149951 & 2 & 2 & 123269 & 21.07 \\
\hline $15: 00(2)$ & 149951 & 2 & 2 & 123496 & 21.11 \\
\hline $15: 30(2)$ & 149951 & 2 & 2 & 122857 & 21.00 \\
\hline $16: 00$ (2) & 149951 & 2 & 2 & 120162 & 20.54 \\
\hline $16: 30(2)$ & 149951 & 2 & 2 & 118301 & 20.22 \\
\hline $17: 00$ (2) & 149951 & 2 & 2 & 117290 & 20.05 \\
\hline $17: 30(2)$ & 149951 & 2 & 2 & 116322 & 19.88 \\
\hline $17: 32(8)$ & 601349 & 1 & 2 & 467484 & 79.90 \\
\hline $17: 47(8)$ & 601349 & 1 & 2 & 469906 & 80.31 \\
\hline
\end{tabular}

case. Most of the rainfall was absorbed by the sediment, limiting the transport of sediment by runoff. Consequently, the sample did not reach full saturation. We suspect that a small quantity of evaporation may have occurred during the experiment; however, we did not weigh the box before and after the experiment, and this minor influence has been neglected in our study.

\subsection{Data acquisition}

The surface evolution was monitored for $6 \mathrm{~h}$ and $46 \mathrm{~min}$ by 12 successive laser scan acquisitions. The first scan and the last scan (acquired at 11:01 and 17:47, respectively) had a point spacing of approximately $0.001 \mathrm{~m}$ with a duration time of $8 \mathrm{~min}$. All the other scans had a $0.002 \mathrm{~m}$ point spacing for a duration of $2 \mathrm{~min}$. From 0 to $50 \mathrm{~m}, 50 \%$ of the laser beam is at a diameter of $4 \mathrm{~mm}$ at full width half height (FWHH) (Leica Geosystems AG, 2007). The scans were acquired vertically from left to right, which means that $1 \mathrm{~cm}$ in width is scanned in less than $2.4 \mathrm{~s}$ for the $2 \mathrm{~min}$ scans and less than $9.6 \mathrm{~s}$ for the $8 \mathrm{~min}$ scans. The scan distance was $2 \mathrm{~m}$. The instrument was not moved throughout the experiment, meaning that the position and the orientation of the scans are identical for all acquisitions. Therefore, no scan alignment was necessary to compare the obtained point clouds.

\subsection{Data processing}

The point clouds were "manually" cleaned of the points that were not imaging the surface of the sample, i.e. the metal casing sides, the background of the scenery and several artefacts, including points not located on the terrain's surface, such as rain drops. Only the surface of the sample was kept. Every cleaned scan has a very high point density: more than
400000 points for the first and last acquisitions and a minimum of 110000 points for the other scans (Table 1).

Each TLS point cloud was first rotated by $45^{\circ}$ to obtain an approximately horizontal point cloud in order to interpolate in 2.5 dimensions. The interpolations were performed using an inverse distance method with a power of 1 (Shepard, 1968) via Surfer 8.0 software (GoldenSoftware, Golden, CO, USA). The point clouds were transformed into a regular squared grid of $1 \mathrm{~mm}$ for the first and last scans and $2 \mathrm{~mm}$ for the other data sets. This provided high-resolution digital elevation models (DEM) of altitude $z$ above the mean horizontal surface. The search radius for DEM generation was defined as 1.5 times higher than the pixel size, i.e. $1.5 \mathrm{~mm}$ for scans with a point spacing of 1 and $3 \mathrm{~mm}$ for the scans with a point spacing of $2 \mathrm{~mm}$ (Fig. 2). Although different values of DEM cell size were tested, this value was chosen as the most satisfactory compromise between accuracy and resolution. The generated DEMs were compared to quantify and map surface changes, i.e. mass movements and erosion/deposition processes. Each DEM was subtracted from the initial (or reference) DEM (DeRose et al., 1998). The resulting $z$ difference grids have negative value pixels for "erosion" and positive value pixels for "deposition". To limit the noise of the measurements, absolute value differences less than $0.0015 \mathrm{~m}$ were ignored; this threshold was obtained by a trial and error procedure.

\section{Results}

The precipitation lasted from 13:30 until the end of the experiment, with a 30 min hiatus starting at approximately 16:00. The maximum rainfall intensity $\left(5.2 \mathrm{~mm} \mathrm{~h}^{-1}\right)$ occurred at $16: 30$. The cumulative precipitation quantity was $5.5 \mathrm{~mm}$ at the end of the experiment. Three different surface pro- 


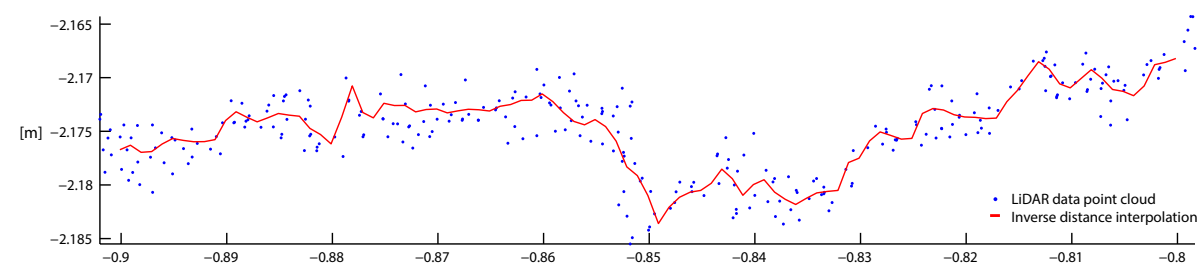

Figure 2. A $10 \mathrm{~cm}$ long downhill section using the points from a $1 \mathrm{~cm}$ wide swath of the original TLS data point cloud compared with the $1 \mathrm{~mm}$ DEM profile (17:47 scan data). The profile has been processed with an inverse distance interpolation with a power of 1.

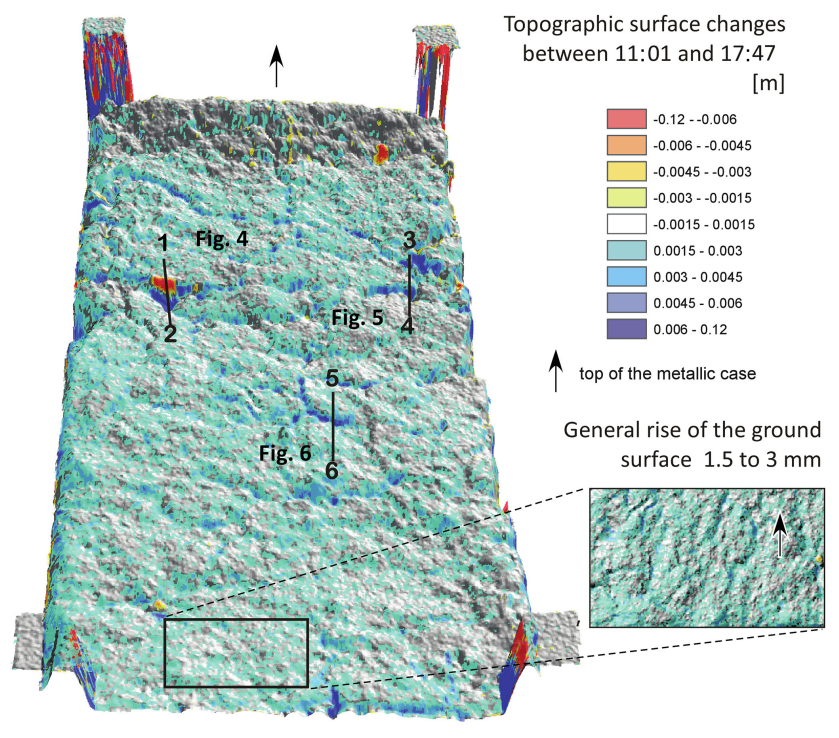

Figure 3. A comparison of TLS scans. The colours represent topographic changes between 11:01 and 17:47. The figure also includes a detailed view of the surface. The locations of Figs. 4, 6 and 7 are indicated.

cesses of topographic changes were identified. Figure 3 shows the difference between the initial and final scans (11:01 and 17:47, respectively). Changes in the surface elevation $(z)$ appear in blue (increased elevation) and red (decreased elevation; Fig. 3). We considered only the changes that are fully visible in the oblique view of the experiment (i.e. the box with a slope of $45^{\circ}$ ).

The micro-topographic changes that occurred along transect 1-2 are shown in Figs. 3 and 4. Figure 4c shows a depression (in red) formed at the top of a small ridge, and the surface elevation of a depression below this ridge increased (in blue). This change can be interpreted as a downward mass movement at the millimetre scale. The small particles moved downward and filled a desiccation crack. This phenomenon occurred $30 \mathrm{~min}$ after the highest intensity rain event, between 17:00 and 17:30 (Fig. 5).

When the rain intensity reached $1 \mathrm{~mm} \mathrm{~h}^{-1}$, the entire surface of the soil started to rise (perpendicular to the surface of the $45^{\circ}$ slope), which appears as a pale blue layer in Fig. 3 and is illustrated in Fig. 6. This process resulted in an over-
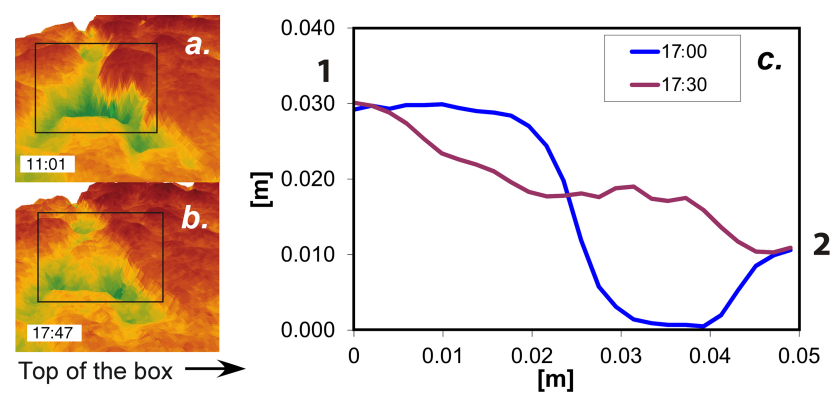

Figure 4. Profile changes showing mass movement occurring between 17:00 and 17:30. (a) A 3-D view of the zone at 11:01 and (b) at 17:47. The black boxes indicate the position of the profiles in (c).

all rise from 1.5 to $3 \mathrm{~mm}$ over the course of the experiment, i.e. a cumulative $5.5 \mathrm{~mm}$ of rain (Fig. 5). The surface elevation increased slowly after the first rain. At 16:30, the surface subsided, and the process was momentarily slowed down. Subsequently, the processes accelerated following the peak in rain intensity (Fig. 5). Note that no significant rise in the topographic surface occurred at the top of the sample, which was protected from the rain (Fig. 3).

Another observed process is linked to changes in the soil surface by lateral expansion (Figs. 6, 7). This process occurred continuously through the closing of desiccation cracks, which were present on the surface of the sample.

The final observed process was the stripping of soil particles by the kinetic energy of the raindrops. Although these changes were observed by the authors during the experiment, their magnitude was unfortunately too small to be significantly monitored by the TLS used in this study.

\section{Discussion and conclusions}

The topographic changes observed along transect 1-2 (Figs. 3 and 4) occurred almost instantaneously, which excludes the rain splashing process. These changes are interpreted as a micro-landslide. Based on the duration of the scans and the size of the transported mass, we assume that it is highly unlikely that a scan had just crossed the region of interest when the movements occurred within it $(0.05 \mathrm{~m}$ scanned in approximately $50 \mathrm{~s}$ ). In addition, the two profiles 


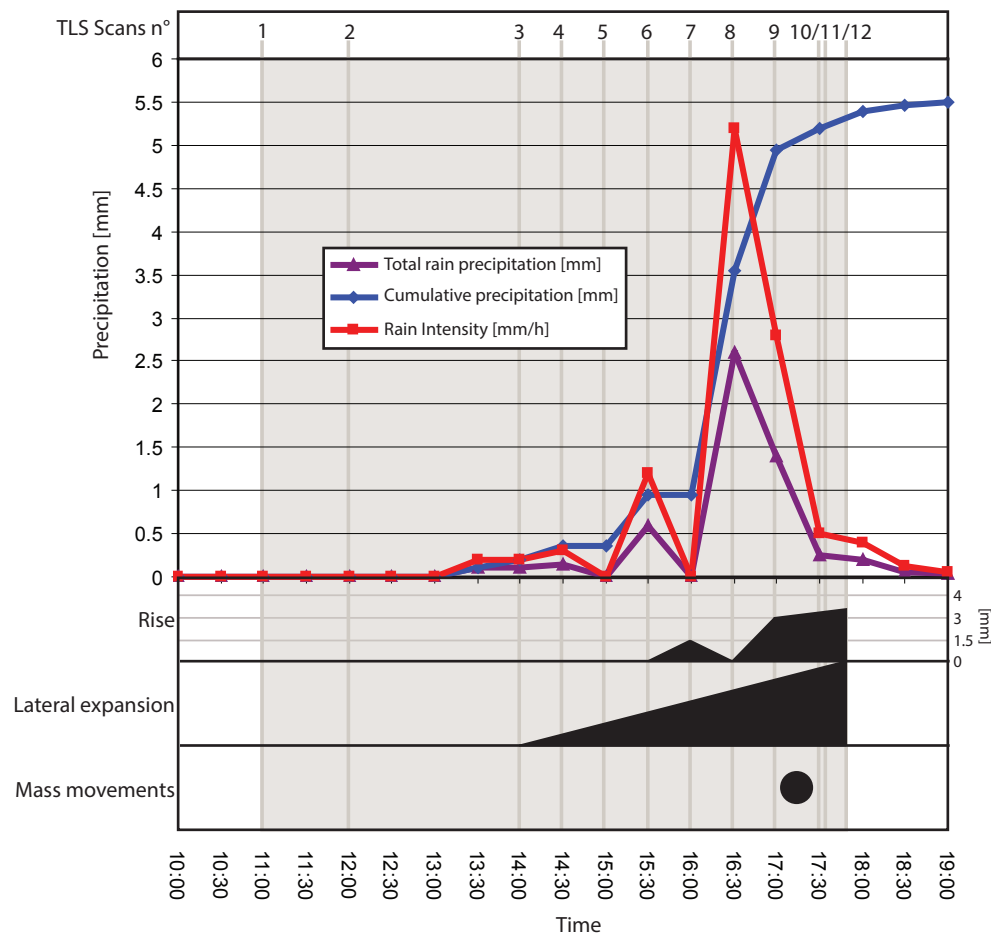

Figure 5. Observed phenomenon relative to the precipitation data. The total rain amount in millimetres, the cumulative precipitation and the rain intensity are presented. The rise is shown in millimetres, and the lateral expansion intensity and mass movement processes are presented in relative scales.

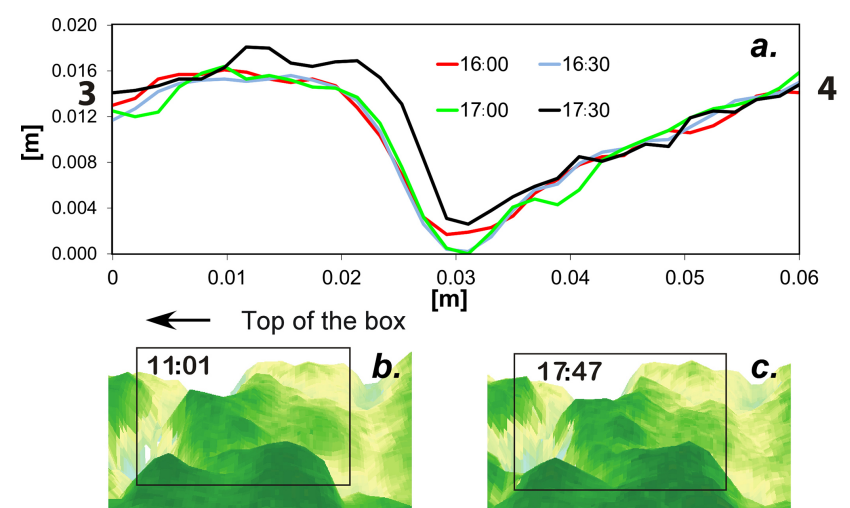

Figure 6. (a) Profile changes showing the evolution of lateral expansion and surface rise between 16:00 and 17:30. (b) A 3-D view of the zone at 11:01 and (c) at 17:47. The black boxes indicate the position of the profiles in (a).

before and after the occurrence of the changes mimic the profile changes usually observed in real landslides. The observed process is likely related to the initiation of miniature debris flows (MDFs) observed by Oostwoud Wijdenes and Ergenzinger (1998); however, MDFs require heavy rainfall.

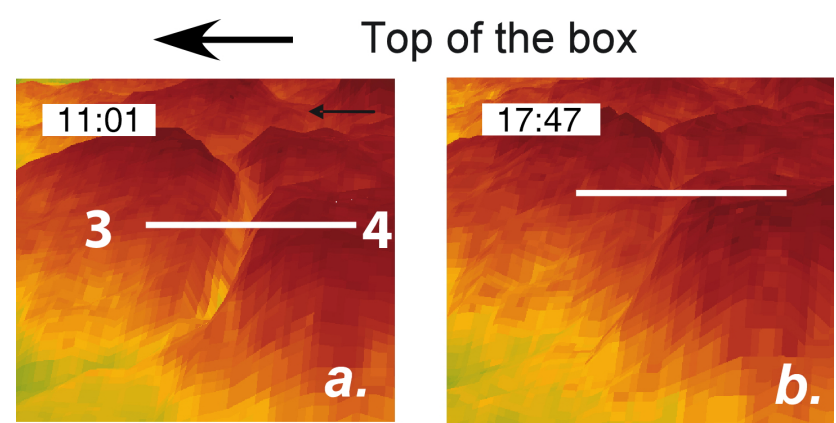

Figure 7. 3-D views of the evolution of lateral expansion, which closes a crack between 11:01 (a) and 17:47 (b).

The observed rise in the surface, which occurred following a 30 min delay after the initiation of rainfall, is certainly linked to the swelling of the material. The soil sample experienced swelling after the first rainfall intensity peak, contraction 30 min after the cessation of rainfall and renewed rising once the rain started again. This measured cyclic behaviour demonstrates that the swelling and contraction of the soil surface is a reversible process. We can assume that this process is linked to moderate rainfall intensities, which allow water to infiltrate the fine-grained material, causing swelling. This process is not necessarily caused by clay minerals because they are present only in small quantities (primarily illite) in 
the study area (Antoine et al., 1995). The swelling dissipates rapidly for moderate rainfall events because of the diffusion of water when the rainfall stops, which leads to a decrease in the effect of the water.

The crack-closing lateral expansion of the surface is also certainly linked to swelling but is not reversed when the rain stops. Figures 6 and 7 clearly show that the material has expanded and that the material has not been transported because no deposition was observed at the bottom. We have not found any definitive explanation that accounts for the difference between the rising process and the lateral expansion process. However, the difference must be related to gravity, which increases the effect of swelling downward. When the two sides of the crack make contact, the moistened zone doubles its thickness, decreasing the water diffusion in the material. In addition, these processes must be components of creeping (Selby, 1993), likely because the retreat by drying is less effective in the downslope portion, leading to slow progressive downward movements.

The above interpretations are also important for the understanding of the infiltration process. Cracks clearly play an important role in the infiltration rates (Mitchell and van Genuchten, 1993; Römkens and Prasad, 2006) and consequently in the destabilisation of slopes (Stumpf et al., 2013; Galeandro et al., 2014). The processes analysed here play a role in the closure of cracks, as shown in Fig. 7. In the present case study, we demonstrated how micro-scale infiltration can influence the degradation of soil surface by inducing downward mass movements that are not reversible.

We have also shown here the great potential of highresolution three-dimensional TLS or photogrammetry point clouds for the analysis of the processes that lead to erosion through surface mass movements at the millimetre scale. Investigations of erosional processes using point clouds are increasing in number. These studies use laser scanners for either micro-scale surface imaging (Schmid et al., 2004; Barneveld et al., 2013) or measuring crack apertures (Sanchez et al., 2013). In addition, photogrammetry and structure from motion (SfM) methods are now being developed to analyse soil surfaces (Snapir et al., 2014).

This paper shows that monitoring the changes at the millimetre scale to examine soil surface changes and erosion is now possible. This development will aid in designing future experiments to analyse certain processes, such as swelling, crack closure, micro-landslides, and initiation of MDFs. With heavier rainfall, sediments will be mobilised and transported across longer distances, enabling the study of MDFs and the formation of rills. This study also demonstrates that material and rain intensity must be suitable to permit the efficient detection of rain splash processes and associated erosion; specifically, a rainfall intensity of greater than $20 \mathrm{~mm} \mathrm{~h}^{-1}$ is necessary (Mathys et al., 2005).
Acknowledgements. The authors would like to thank the Observatoire de Recherche en Environnement (ORE) of Draix for letting us sample soil in a protected area. We would also like to thank the UNIBAT service of the University of Lausanne (UNIL) for providing meteorological data from their weather station. We also greatly appreciate the comments and suggestions of our colleagues M.-H. Derron, Benjamin Rudaz and Antonio Abellán. We thank American Journal Experts for the improvements of the English language of this paper.

We dedicate this paper to the first author Jacques Bechet, who died in a snow avalanche 3 days after the acceptance of this paper. The content of this paper is an expression of its great ingenuity, curiosity and research spirit he shared with his co-worker Julien Duc. We will ever remember his enthusiasm.

Edited by: M. Mikos

\section{References}

Antoine, P., Giraud, A., Meunier, M., and Van Asch, T.: Geological and geotechnical properties of the 'terres noires' in southeastern France: Weathering, erosion, solid transport and instability, Eng. Geol., 40, 223-234, 1995.

Barneveld, R.-J., Seeger, M., and Maalen-Johansen, I.: Assessment of terrestrial laser scanning technology for obtaining highresolution DEMs of soils, Earth Surf. Proc. Land., 38, 10969837, 2013.

Caris, J.P.T. and Van Asch, T.: Geophysical, geotechnical and hydrological investigations of a small landslide in the French Alps, Eng. Geol., 31, 249-276, 1991.

DeRose, R. C., Gomez, B., Marden, M., and Trustrum, N. A.: Gully erosion in Mangatu Forest, New Zealand, estimated from digital elevation Models, Earth Surf. Proc. Land., 23, 1045-1053, 1998.

Galeandro, A., Doglioni, A., Simeone, V., and Šimůnek, J. S.: Analysis of infiltration processes into fractured and swelling soils as triggering factors of landslides, Environ. Earth Sci., 71, 29112923, 2014.

Leica Geosystem AG: Leica ScanStation 2 technical note, Vl. 07, Heerbrugg, Switzerland, 2007.

Malet, J.-P., Durand, Y., Remaître, A., Maquaire, O., Etchevers, P., Guyomarc'h, G., Déqué, M., and van Beek, L. P. H.: Assessing the influence of climate change on the activity of landslides in the Ubaye Valley, in: Proceedings of the International Conference on Landslides and Climate Change - Challenges and Solutions, edited by: McInnes, R., Jakeways, J., Fairbank, H., and Mathie, E., Taylor \& Francis, London, 195-205, 2007.

Maquaire, O., Ritzenthaler, A., Fabre, D., Ambroise, B., Thiery, Y., Truchet, E., Truchet, E., and Malet, J.-P.: Caractérisation des profils de formations superficielles par pénétrometrie dynamique à énergie variable: application aux marnes noires de Draix (Alpesde-Haute-Provence, France), Comptes Rendus Géosciences, 334, 835-841, 2002.

Mathys, N., Klotz, S., Esteves, M., Descroix, L., and Lapetite, J.M.: Runoff and erosion in the Black Marls of the French Alps: observations and measurements at the plot scale, Catena, 63, 261-281, 2005. 
Mitchell, A. R. and van Genuchten, M. T. H.: Flood irrigation of a cracked soil, Soil Sci. Soc. Am. J., 57, 490-497, 1993.

Oostwoud Wijdenes, D. J. and Ergenzinger, P.: Erosion and sediment transport on steep marly hillslopes, Draix, Haute-Provence, France: an early experimental field study, Catena, 33, 179-200, 1998.

Römkens, M. J. M. and Prasad, S. N.: Rain Infiltration into swelling/shrinking/cracking soils, Agr. Water Manage., 86, 96205, 2006

Sanchez, M., Atique, A., Kim ,S., Romero, E., and Zielinski, M.: Exploring desiccation cracks in soils using a 2D profile laser device, Acta Geotechnica, 8, 583-596, 2013.

Schmid, T., Schack-Kirchner, H. and Hildebrand, E.: A Case Study of Terrestrial Laser-Scanning in Erosion Research: Calculation of Roughness Indices and Volume Balance at a Logged Forest Site. Eds: M. Thies, B. Koch, H. Spiecker and H. Weinacker: Laser-Scanners for Forest and Landscape Assessment. ISPRS Archives - V. XXXVI-8/W2 - WG VIII/2, 114-118, 2004.
Selby, M. J.: Hillslope materials and processes, Oxford University Press, Oxford, UK, 252-258, 1993.

Shepard, D.: A two dimensional interpolation function for irregularly-spaced data, New York, USA, Proceeding ACM '68 Proceedings of the 1968 23rd ACM national conference, New York, USA, 517-524, 1968.

Snapir, B., Hobbs, S., and Waine, T. W.: Roughness measurements over an agricultural soil surface with Structure from Motion, ISPRS J. Photogramm. Remote Sens., 96, 210-223, 2014.

Stumpf, A., Malet, J.-P., Kerle, N., Niethammer, U., and Rothmund, S.: Image-based mapping of surface fissures for the investigation of landslide dynamics, Geomorphology, 186, 12-27, 2013.

Torri, D., Regüés, D., Pellegrini, S., and Bazzoffi, P.: Within-storm surface dynamics and erosive effects of rainstorms, Catena, 38, 131-150, 1999. 